Article

\title{
Synthesis of Hollow PVP/Ag Nanoparticle Composite Fibers via Electrospinning under a Dense $\mathrm{CO}_{2}$ Environment
}

\author{
Xin $\mathrm{Hu}^{1}$, Jiayang He ${ }^{1}$, Li Zhu ${ }^{1}{ }^{\mathbb{D}}$, Siti Machmudah ${ }^{2}$, Wahyudiono ${ }^{1} \mathbb{D}$, Hideki Kanda $^{1, * \mathbb{D}}$ \\ and Motonobu Goto $1, *$ (D) \\ 1 Department of Materials Process Engineering, Nagoya University, Furo-cho, Chikusa-ku, \\ Nagoya 464-8603, Japan; hu.xin@i.mbox.nagoya-u.ac.jp (X.H.); he.jiayang@h.mbox.nagoya-u.ac.jp (J.H.); \\ zhu.li@g.mbox.nagoya-u.ac.jp (L.Z.); wahyudiono@b.mbox.nagoya-u.ac.jp (W.) \\ 2 Department of Chemical Engineering, Institut Teknologi Sepuluh Nopember, Surabaya 60111, Indonesia; \\ machmudah@chem-eng.its.ac.id \\ * Correspondence: kanda.hideki@material.nagoya-u.ac.jp (H.K.); \\ goto.motonobu@material.nagoya-u.ac.jp (M.G.); Tel.: +81-52-789-3392 (M.G.)
}

Citation: $\mathrm{Hu}, \mathrm{X} . ; \mathrm{He}$, J.; Zhu, L.; Machmudah, S.; Wahyudiono; Kanda, H.; Goto, M. Synthesis of Hollow PVP/Ag Nanoparticle Composite Fibers via Electrospinning under a Dense $\mathrm{CO}_{2}$ Environment Polymers 2022, 14, 89. https:// doi.org/10.3390/polym14010089 Academic Editor: Francesco Galiano

Received: 28 November 2021 Accepted: 25 December 2021 Published: 27 December 2021

Publisher's Note: MDPI stays neutral with regard to jurisdictional claims in published maps and institutional affiliations.

Copyright: (C) 2021 by the authors. Licensee MDPI, Basel, Switzerland. This article is an open access article distributed under the terms and conditions of the Creative Commons Attribution (CC BY) license (https:// creativecommons.org/licenses/by/ $4.0 /)$.

\begin{abstract}
Polyvinylpyrrolidone (PVP) is used in a wide variety of applications because of its unique chemical and physical features, including its biocompatibility and low toxicity. In this study, hollow $\mathrm{PVP} /$ silver nanoparticle (PVP/Ag NP) composite fibers were synthesized. Stable, spherical Ag NPs, with an average size of $14.4 \mathrm{~nm}$, were produced through a facile sonochemical reduction method. A small amount of starch as a potent reducing and stabilizing agent was used during the reduction of Ag ions to Ag NPs. The fabricated Ag NPs were then added to a $10 \mathrm{wt} \%$ PVP-dichloromethane (DCM) solution, which was utilized as an electrospinning feed solution under a dense carbon dioxide $\left(\mathrm{CO}_{2}\right)$ environment at $313 \mathrm{~K}$ and $5 \mathrm{MPa}$ and an applied voltage of $15 \mathrm{kV}$. The dense $\mathrm{CO}_{2}$ enabled rapid extraction of DCM from the PVP-Ag NPs-DCM solution, which was then dissolved into PVP/Ag NPs, resulting in a hollow structure. Scanning electron microscopy, Fourier-transform infrared (FT-iR) spectroscopy, X-ray diffraction (XRD) and X-ray photoelectron spectroscopy (XPS) analyses, and thermogravimetric analysis (TGA), were used to characterize the electrospinning products.
\end{abstract}

Keywords: silver nanoparticles; ultrasonic; electrospinning; hollow fibers; dense $\mathrm{CO}_{2}$

\section{Introduction}

Silver nanoparticles (Ag NPs) have been used in a wide variety of applications, such as biochemical sensing [1], antibacterial coatings [2], and catalysis [3], because of their unique physicochemical properties, which differ from those of their bulk counterparts. They have been synthesized through numerous methods, such as photochemical methods [4], laser ablation [5], chemical reduction [6], and electrochemical techniques [7]. However, most of these synthesis routes produce low yields of Ag NPs and often require the use of hazardous organic solvents, which pose significant environmental and biological risks.

Sonochemical methods have been utilized for the fabrication of nanomaterials, especially noble material NPs, such as Au [8], Ag [9], and Pt [10]. Recent studies report the use of organic molecules under ultrasonic irradiation due to their comparably excellent reductive capability and fair interaction with the particles, which prevents their oxidation and agglomeration [11]. Starch has been identified as an effective surfactant for the fabrication of Ag NPs in some processes because of its biocompatibility and nontoxicity. Kumar et al. [12] successfully synthesized Ag NPs using starch under ultrasonic irradiation. The formation of spherical Ag NPs using sago starch as a coating agent has also been reported [13].

Electrospinning is a facile technology for fabricating micro- and nanosized polymeric fibers. It has attracted considerable research attention because of its capacity to produce fibers at a large scale. In a conventional electrospinning device, a high-voltage electric area 
is created between a grounded collector and a spinneret. A syringe pump then feeds the polymer solution via a spinneret into the high-voltage electric area. Hence, the electrostatic force created, rather than the mechanical force, drives the electrospinning process. The synthesized fibers exhibit high surface area-to-volume ratios, which make them suitable as nanoparticle carriers in tissue engineering [14] and controlled-release applications [15] and as electronic sensors [16]. Currently, there has been considerable advancement in the possible applications of hollow fibers in medical applications [17], for gas separation technologies [18], and even in catalysis [19]. Hollow fibers are commonly produced through coaxial capillary or template-assisted methods, where the hollow structure is created through the thermal degradation or selective dissolution of the fiber core. In contrast, we have reported the fabrication of hollow, nano-, and microfibers under sub- and supercritical $\mathrm{CO}_{2}$ [20]. Therein, PVP was added to a dichloromethane (DCM) solvent. Subcritical and supercritical $\mathrm{CO}_{2}$ acts as a poor solvent for various polymers [21] and can solubilize most organic solvents, including acids, alcohols, and DCM. Therefore, the interaction between the DCM solution and the dense $\mathrm{CO}_{2}$ environment caused the generation and growth of the $\mathrm{CO}_{2}$-rich voids during the electrospinning process, thereby forming hollow PVP fibers.

In our previous study, Wahyudiono et al. [22,23] have successfully fabricated hollow structure of poly (methyl methacrylate) (PMMA) and PVP by combining the electrospinning with pressurized $\mathrm{CO}_{2}$, respectively. To fabricate the hollow structure, several parameters of this process have been optimized. In addition, Ozawa et al. [24] have successfully produced the hollow $\mathrm{PVP}^{-\mathrm{TiO}_{2}} \mathrm{NPs}$ (titanium dioxide nanoparticles) composite fibers. In addition, the isoelectric point of metal oxides varies with the type and size of the metal. For example, as the particle size increases from $6 \mathrm{~nm}$ to $104 \mathrm{~nm}$, the isoelectric point of titanium dioxide decreases from 6.0 to 3.8 [25]. However, it is not clear whether the same phenomenon occurs with metal nanoparticles since the metal oxides and metals have different isoelectric points due to the presence or absence of oxygen atoms, which can result in the different interaction with PVP polymers. Hence, we attempted to fabricate hollow PVP-metal nanoparticles composite fibers, something has not been explored so far.

In this study, a novel method for producing hollow PVP/Ag NP composite fibers was reported. Ag NPs were synthesized under ultrasonic irradiation using starch as a stabilizing agent. Then, the produced Ag NPs were added to PVP-DCM, which was the precursor solution for the synthesis of the hollow nano- and microfibers. The properties of PVP, such as high solubility in water and organic solvents, low toxicity, excellent film-forming capabilities, and good binding characteristics, make them suitable for the electrospinning process. The characteristics of the products were investigated. Ag NPs imparted antibacterial properties to the electrospun PVP fibers, making the hollow PVP/Ag NPs composite fibers ideal for biomedical applications [26]. The electrospun PVP fibers have high surface area-to-volume ratios because of their hollow morphology. As a result, more Ag NPs were exposed on the surface, thereby enhancing the antibacterial characteristics of the composite fibers [27].

\section{Experimental Procedures}

\subsection{Materials}

A silver nitrate solution $\left(\mathrm{AgNO}_{3}\right.$, Wako Pure Chemical Industries, Osaka, Japan) was used as the raw material for the ultrasonic process. The starch and distilled water used herein were procured from the same supplier. For the electrospinning process, PVP (MW $1,300,000$ ) (Sigma-Aldrich, Tokyo, Japan) was the solute in the feed solution, whereas DCM (99.0\% purity, Wako Pure Chemical Industries) was used as the solvent. Lastly, carbon dioxide $\left(\mathrm{CO}_{2}, 99 \%\right.$ purity) was purchased from Sogo Kariya Sanso, Inc., Kariya, Japan.

\subsection{Synthesis and Characterization of $A g N P S$}

Starch $(10 \mathrm{mg})$ was added to a $10 \mathrm{~mL}-10 \mathrm{mM} \mathrm{AgNO}_{3}$ solution in a glass bottle. To ensure full dissolution of the surfactant, the mixture was stirred and then agitated ultrasonically. Figure 1 shows the schematic of the ultrasonic irradiation apparatus. The 
mixed solution was put into the stainless steel vessel (TVS-1, $50 \mathrm{~mL}$, Taiatsu Techno Corp., Saitama, Japan). The distance between the vessel and sonicator is approximately $5 \mathrm{~cm}$. The solution was then placed in a water bath maintained at $50{ }^{\circ} \mathrm{C}$. Ultrasonic irradiation was carried out using Ultrasonic Multi Cleaner W-118 (Honda Electronics Company, Toyohashi, Japan). Irradiation was done at 28, 45, $100 \mathrm{kHz}$, and $600 \mathrm{~W}$ (input) for 40, 80, and $120 \mathrm{~min}$.

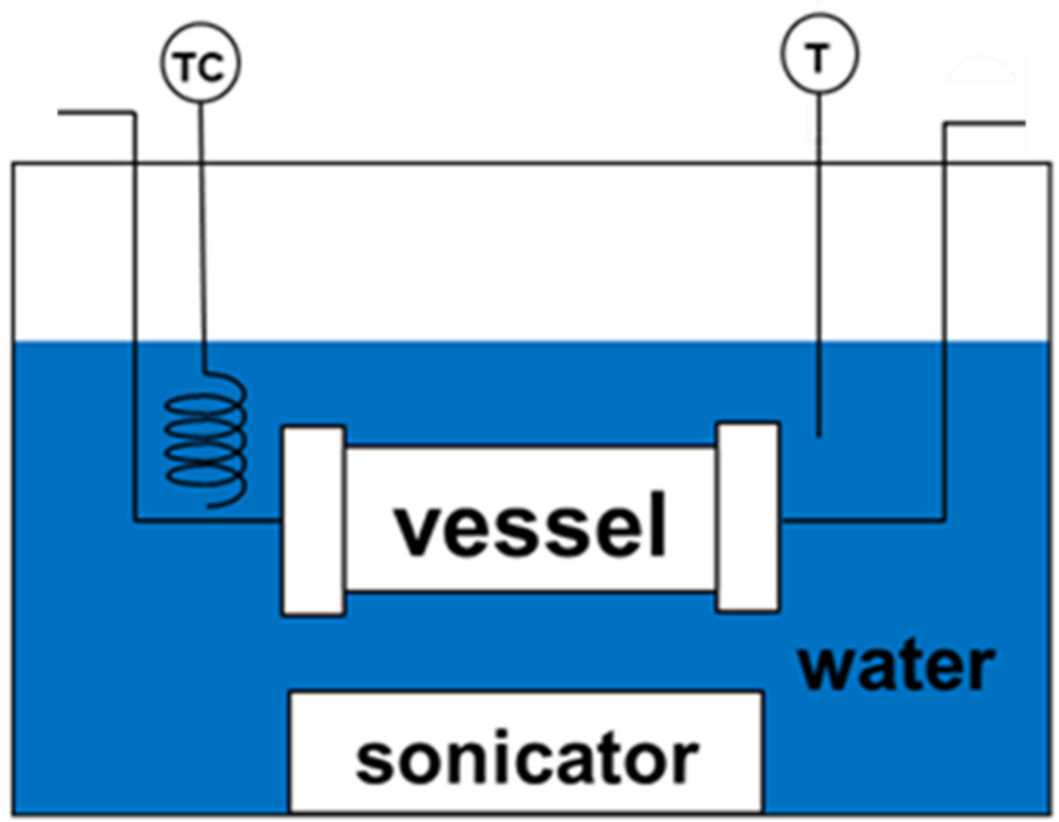

Figure 1. Ultrasonic irradiation apparatus for the synthesis of Ag NPs.

The optical characteristics of the Ag NPs colloidal solution were investigated using ultraviolet-visible (UV-vis) spectrometry (V-550, JASCO Corporation, Tokyo, Japan). To investigate the morphology and elemental spectra of the produced Ag NPs, transmission electron microscopy (TEM, JEM-2100Plus, JEOL, Tokyo, Japan) with energy-dispersive X-ray spectroscopy (EDX, JED-2300T and Gatan, GIF Quantum ER, JEOL) was done. For such analysis, the Ag NP colloidal solution was dipped onto a TEM grid. From the obtained TEM images, the size distribution of the synthesized Ag NPs was analyzed using ImageJ ver. 1.42, and at least 250 nanoparticles were counted for analysis.

\subsection{Feed Solution Preparation for Electrospinning}

The polymer solution was produced by dissolving 6, 8, and $10 \mathrm{wt} \%$ PVP in DCM. Then, a $1 \mathrm{~mL}$ Ag NP solution was added to the polymer solution. Prior to this addition, the colloidal Ag NPs solution was freeze-dried using FDU-1200 (EYELA, Tokyo Rikakikai Co, Ltd., Tokyo, Japan).

\subsection{Synthesis of the Hollow PVP and PVP/Ag NPS Composite Fibers}

Figure 2 shows the apparatus used for the electrospinning process, which included a non-conductive polyetheretherketone (PEEK) cylindrical chamber (inner diameter $6 \mathrm{~cm}$; length $20 \mathrm{~cm}$; AKICO, Tokyo, Japan) with cartridge heaters coupled with an electric fan, high-pressure pump (PU-1586, JASCO), back-pressure regulator (BPR) (HPB-450 SUS-316, AKICO), high-pressure syringe pump (PHD-Ultra 4400, Harvard Apparatus, Holliston, MA, USA), high-voltage (HV) power supply unit (HARb-30P1, Matsusada Precision Inc., Tokyo, Japan), and an $8 \mathrm{~mL}$ stainless-steel syringe. The nozzle-to-collector distance was $8 \mathrm{~cm}$. The PEEK chamber was heated to $314 \pm 3 \mathrm{~K}$. The temperature of the electrospinning process was regulated using a thermocouple, which was installed inside and was put in direct contact with the space of the PEEK vessel. In contrast, K-type thermocouples were installed on the vessel walls to monitor the radial temperature distribution in the PEEK chamber. After the desired temperature was reached, $\mathrm{CO}_{2}$ was pumped into the vessel 
using a PEEK capillary tube to the desired pressure, which was maintained using a BPR. As the necessary conditions were achieved, the polymer feed solution was injected by the high-pressure syringe pump into the chamber through the capillary tube at a flow rate of $0.05 \mathrm{~mL} / \mathrm{min}$. Simultaneously, an electrostatic force was generated at $15 \mathrm{kV}$ using the $\mathrm{HV}$ power supply. In this device, the polymer solution and $\mathrm{CO}_{2}$ were moved separately using a nozzle and were then placed in the stainless-steel flange (anodic electrode). Each experiment was carried out for $20 \mathrm{~min}$ and was repeated two to four times to obtain reliable results.

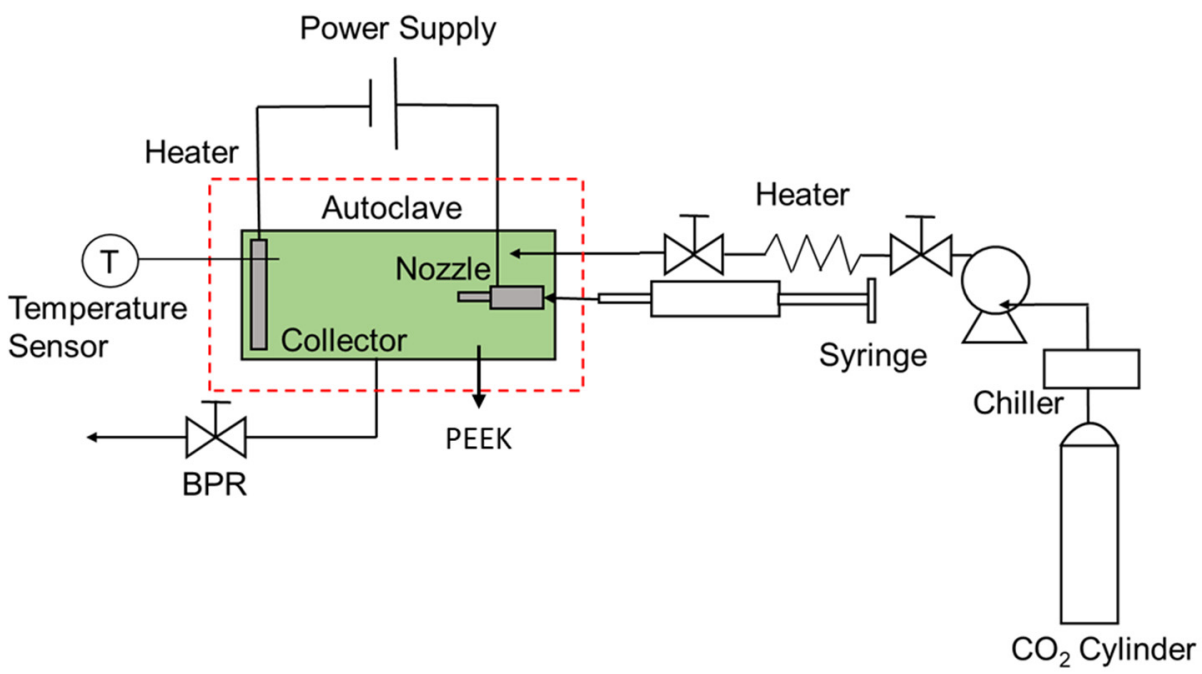

Figure 2. Schematic representation of the electrospinning system.

\subsection{Characterization of the Hollow PVP and PVP/Ag NPs Composite Fibers}

The morphology of the produced fibers was examined using SEM (S-4300, Hitachi, Tokyo, Japan) after gold coating (IB-3, Eiko Engineering, Tokyo, Japan). The gold coating was approximately $10 \mathrm{~nm}$ thick. ImageJ version 1.42 software was used to determine fiber diameter from the SEM images, and the number of fibers counted for analysis was at least 300. The functional groups on the surfaces of the electrospun fibers generated under each experimental condition were identified through FT-IR spectroscopy (Spectrum Two FT-IR spectrophotometer, PerkinElmer Ltd., Waltham, MA, USA) in the attenuated total reflectance (ATR) mode (golden single reflection ATR system, P/N 10,500 series, Specac) at $4 \mathrm{~cm}^{-1}$ resolution from $4000-500 \mathrm{~cm}^{-1}$. The structures of the fibers were investigated using X-ray diffraction (XRD; FR-E X-ray diffractometer with $\mathrm{Cu} \mathrm{K} \alpha$ radiation $(\lambda=1.542 \AA)$ ). The beam size was approximately $300 \mu \mathrm{m} \times 300 \mu \mathrm{m}$, whereas the camera length was approximately $70 \mathrm{~mm}$. The fiber samples were placed on a glass substrate and treated with an X-ray beam without additional modifications. The thermal behavior of the electrospun fibers was evaluated using thermogravimetric/differential thermal analyses (TG 8120; Thermo plus, Rigaku, Corp., Tokyo, Japan). Surface elemental compositions of the products were studied using XPS (ESCA-3300, Shimadzu-Kratos, Kyoto, Japan) at a collecting angle of $45^{\circ}$ from the average.

\section{Results and Discussion}

\subsection{Fabrication and Characterization of the Ag NPs Synthesized by Ultrasonic Irradiation}

The unique optical properties of Ag NPs, that is, the localized surface plasmon resonance (LSPR), are dependent on their shape, diameter, surface structure, and aggregation state, which makes them ideal materials for various applications. Figure 3 shows the UV spectra of the Ag NP solutions fabricated through ultrasonic irradiation at different frequencies and sonication durations. An intense peak at the spectra of the Ag NP solution occurs approximately at $405 \mathrm{~nm}$, which was also observed in the spectra of chemically prepared Ag NPs reported in literature [28]. Figure 3a shows the optical absorbance of the 
colloidal Ag NP solutions obtained at different ultrasonic frequencies $(28,45$, and $100 \mathrm{kHz})$ and irradiation for $40 \mathrm{~min}$. The color of the Ag NP solution changed from transparent $(100 \mathrm{kHz})$ to yellow $(45 \mathrm{kHz})$, and, finally, to dark brown $(28 \mathrm{kHz})$, which indicates a change in the rate of reduction of $\mathrm{AgNO}_{3}$ to $\mathrm{Ag}$ NPs [29]. The absorbance of the Ag NP solution decreased as the ultrasonic frequency increased. Furthermore, the intensity of the peak at $405 \mathrm{~nm}$ decreased with increasing ultrasonic frequency, which implies that the formation rate of Ag NPs in the colloidal solution decreased with increasing frequency [30]. Previous reports show that the following reactions occur during the sonochemical reduction of metal nanoparticles in the presence of organic additives (reactions 1-4) [31].

$$
\begin{gathered}
\mathrm{H}_{2} \mathrm{O} \rightarrow{ }^{\bullet} \mathrm{H}+{ }^{\bullet} \mathrm{OH} \\
2 \mathrm{RH}+{ }^{\bullet} \mathrm{OH}\left({ }^{\bullet} \mathrm{H}\right) \rightarrow 2^{\bullet} \mathrm{R}+\mathrm{H}_{2} \mathrm{O}\left(\mathrm{H}_{2}\right) \\
\mathrm{RH} \rightarrow \text { radicals and unsteady products } \\
\mathrm{Ag}(\mathrm{I})+\text { reducing species }\left({ }^{\bullet} \mathrm{H},{ }^{\bullet} \mathrm{R} \text {, etc. }\right) \rightarrow \mathrm{Ag}(0)
\end{gathered}
$$

where RH is the organic additive. Reactions (1)-(3) demonstrate the sonochemical fabrication of the reducing radicals and reductants: (1) the sonolysis of water produces ${ }^{\bullet} \mathrm{H},(2)$ the abstraction reaction of $\mathrm{RH}$ with ${ }^{\bullet} \mathrm{OH}$ or ${ }^{\bullet} \mathrm{H}$ produces ${ }^{\bullet} \mathrm{R}$ and $\mathrm{H}_{2}$, and (3) the pyrolysis of $\mathrm{RH}$ and water produces radicals and unsteady compounds. Finally, $\mathrm{Ag}(\mathrm{I})$ reduction occurs through many complex reaction steps utilizing the produced reducing species in the previous reactions [32]. Low sonication frequencies can create relatively large bubbles that collapse more forcefully than higher frequencies, thus promoting the generation of more reducing radicals and reductants. Furthermore, low frequencies can motivate collisions between molecules and clusters in the solution, thereby accelerating the reduction of $\mathrm{AgNO}_{3}$ to form Ag NPs.
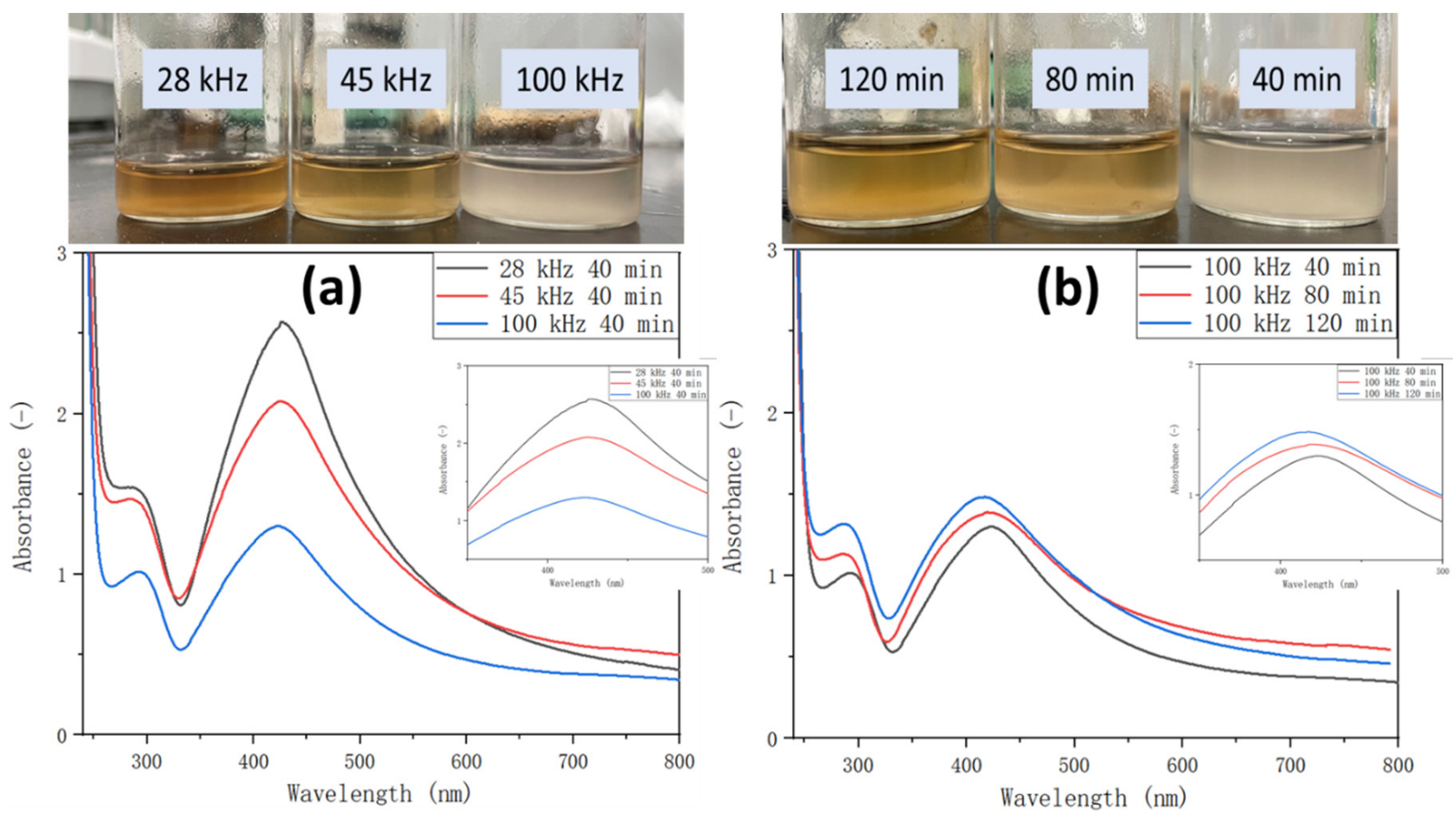

Figure 3. (a) UV spectra of the colloidal Ag NP solutions produced through ultrasonic irradiation at different frequencies $(28,45$, and $100 \mathrm{kHz})$ for $40 \mathrm{~min}$ sonication duration, and (b) different ultrasonic times $(40,80$, and $120 \mathrm{~min})$ at frequency of $100 \mathrm{kHz}$. 
Figure $3 \mathrm{~b}$ shows the UV spectra of the Ag NP solutions obtained at different ultrasonic times $(40,80$, and $120 \mathrm{~min})$ at a frequency of $100 \mathrm{kHz}$. The nanoparticle solution was transparent after ultrasonication for $40 \mathrm{~min}$. Its color turned yellow after $80 \mathrm{~min}$ and darkened after $120 \mathrm{~min}$. The observed transition in the color is possibly due to the change in the Ag NP concentration in the solution with varying ultrasonication durations. Furthermore, the absorbance of the solution increased with increasing ultrasonic time, which corresponds well to the previous conclusion. Longer ultrasonication times imply more time for the reduction of $\mathrm{AgNO}_{3}$ to $\mathrm{Ag}$ NPs; hence, increasing $\mathrm{Ag}$ NP concentration was observed with prolonged sonication. In addition, the LSPR band shifted toward a shorter wavelength area (Figure 3a,b), when the ultrasonic frequency and the sonication time were increased. This shift indicates a reduction in the Ag NP particle size. The mechanism of such phenomenon will be discussed in the next section.

Figure 4 shows the TEM images, the selected area electron diffraction (SAED) graphs, and size distribution of the Ag NPs fabricated at different ultrasonic irradiation frequencies and times. The synthesized Ag NPs are dispersed and have spheroidal morphologies. The observed diffuse bands in the SAED patterns can be indexed to the (111), (200), (220), and (311) diffraction planes of Ag, which helps determine the phase of the NPs [33]. No discernible differences were observed on changing the ultrasonic parameters, indicating that the frequency and ultrasonic time had no major effect on the crystallinity of the produced Ag NPs. However, ultrasonic parameters were found to have a considerable effect on the size of the nanoparticles. Smaller nanoparticles, by definition, exhibit greater surface area-to-volume ratios, resulting in superior properties. For instance, smaller Ag NPs were reported to have better antibacterial characteristics [34]. The particle size distribution plots show that the size of the fabricated Ag NPs decreased with increasing frequency (Figure $4 \mathrm{a}-\mathrm{c}$ ) and ultrasonic time (Figure $4 \mathrm{c}-\mathrm{e}$ ). Ultrasonic irradiation of the solution generates transient cavitation: bubble formation, growth, and implosive collapse. When a bubble bursts, it creates intense shock waves that spread faster than the speed of sound through the liquid, causing unique sonochemical reactions and high-velocity collisions among the solid particles suspended in the liquid [35]. At $28 \mathrm{kHz}$ ultrasonic frequency, high collisions occurred among the Ag NPs, which resulted in the fusion of the nanoparticles, atoms, or electrons formed from localized melting. This phenomenon can be alleviated at 45 and $100 \mathrm{kHz}$ frequency, hence the decreasing Ag NPs size with increasing ultrasonic frequencies. The findings of this study are in good agreement with those of previous reports. Suslick et al. [36] reported that metal particles that have a mean size of 5-10 $\mu \mathrm{m}$ were aggregated by ultrasonic irradiation at $20 \mathrm{kHz}$. Okitsu et al. [31] also generated $\mathrm{Au}$ NPs using sonochemical reduction of $\mathrm{Au}$ (III) ions and found that nanoparticle size decreased with higher ultrasonic frequency during sonication at $20-213 \mathrm{kHz}$ frequencies. In case of ultrasonic time, longer ultrasonic times prevented the aggregation of the NPs, thus reducing the size of the synthesized Ag NPs. A similar finding was reported in the synthesis of zinc oxide NPs through sonication [37].

Elemental characterization was carried out using EDX analysis. Figure 5a shows the EDX spectra of the Ag NPs synthesized at $100 \mathrm{kHz}$ with sonication for $120 \mathrm{~min}$. Strong signals relating to the elemental silver region $(3 \mathrm{keV})$ in the EDX spectrum indicate the formation of Ag NPs in the solution products. Peaks corresponding to silver, copper $(\mathrm{Cu})$, carbon $(\mathrm{C})$, oxygen $(\mathrm{O})$, and nitrogen $(\mathrm{Ni})$ were also observed in the EDX spectra. The $\mathrm{Cu}$ and $C$ peaks observed may be attributed to the TEM grid utilized to load the Ag NPs. In contrast, the peaks corresponding to $\mathrm{O}$ and $\mathrm{N}$ are attributed to the starch molecule attached to the surface of the $\mathrm{Ag}$ NPs and from the $\mathrm{AgNO}_{3}$ solution, respectively. Besides, there is an unidentified peak at $1.7 \mathrm{keV}$ in Figure $5 \mathrm{a}$. The characteristics $\mathrm{X}$-ray (keV), which are around $1.7 \mathrm{keV}$, are Si (1.739 keV), Rb (1.694 keV), Hf (1.644 keV), Ta (1.709 keV) and W $(1.774 \mathrm{keV})$. These elements could not be contained in the sample. The unidentified peak may be caused by the noise or contamination from the sonochemical process. 
(a) $28 \mathrm{kHz} 40 \mathrm{~min}$

(b) $45 \mathrm{kHz} 40 \mathrm{~min}$
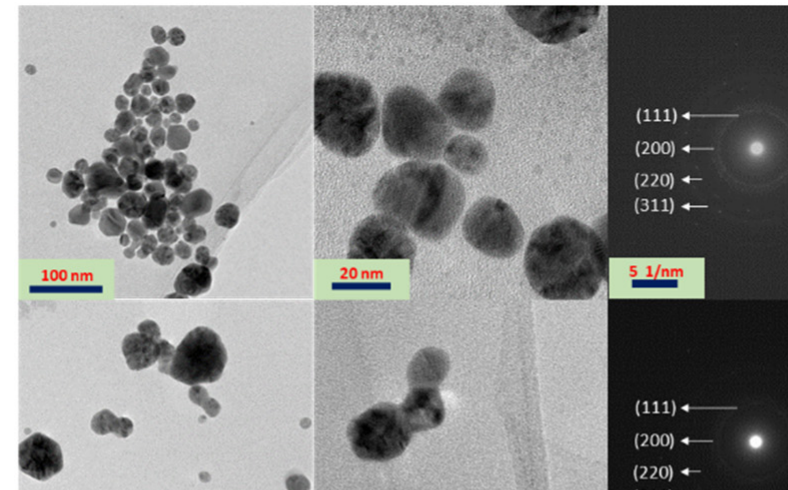

$(311) \leftarrow$

(c) $100 \mathrm{kHz} 40 \mathrm{~min}$

(d) $100 \mathrm{kHz} 100 \mathrm{~min}$

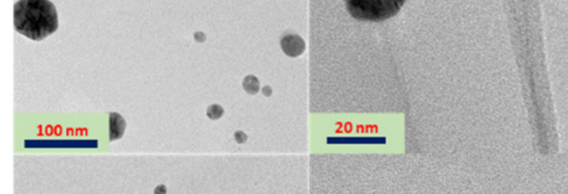

5
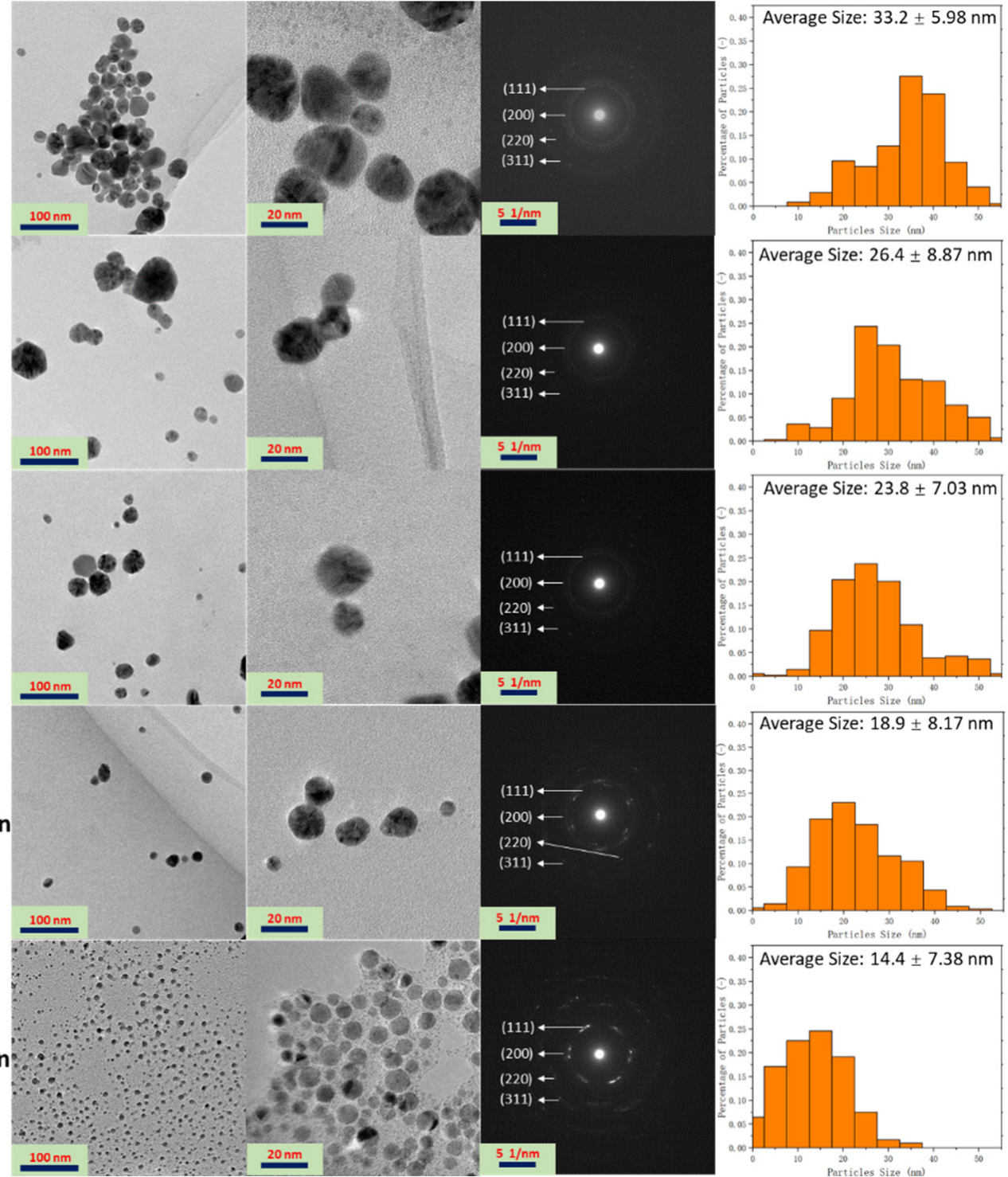

(e) $100 \mathrm{kHz} 120 \mathrm{~min}$

Figure 4. TEM images and SAED patterns of Ag NPs fabricated at different ultrasonic irradiation frequencies (28, 45, and $100 \mathrm{kHz}$ ) and durations (40, 80, and $120 \mathrm{~min}$ ), (a) $28 \mathrm{kHz} 40 \mathrm{~min}$; (b) $45 \mathrm{kHz}$ $40 \mathrm{~min}$; (c) $100 \mathrm{kHz} 40 \mathrm{~min}$; (d) $100 \mathrm{kHz} 100 \mathrm{~min}$; (e) $100 \mathrm{kHz} 120 \mathrm{~min}$.

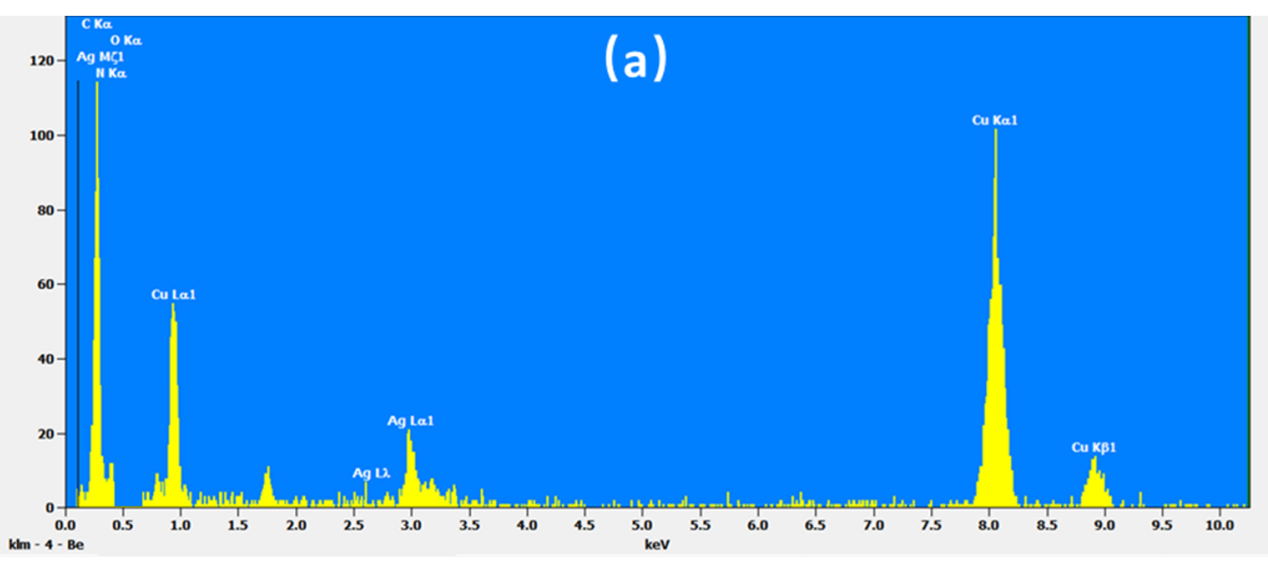

Figure 5. Cont. 


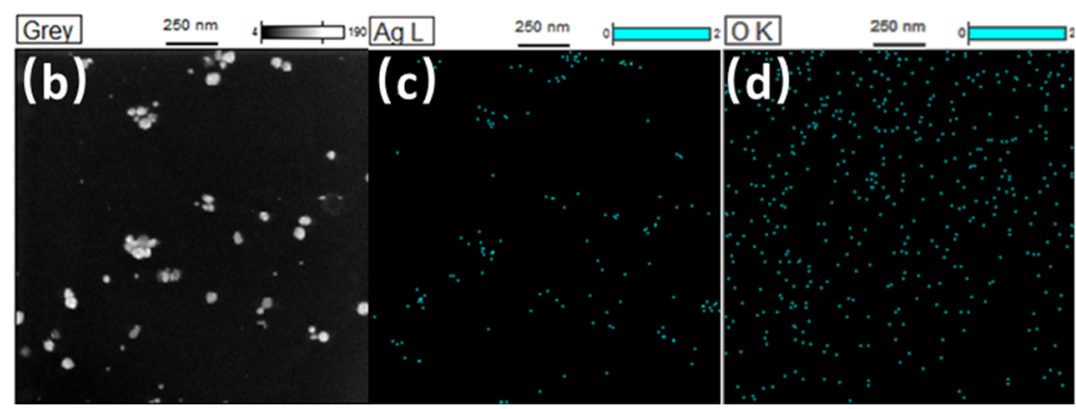

Figure 5. EDX spectra (a) and dark-field TEM image of Ag NPs (b) with the corresponding EDX map for silver (c) and oxygen (d) (ultrasonic frequency: $100 \mathrm{kHz}$, ultrasonic time: $120 \mathrm{~min}$ ).

\subsection{Fabrication and Characterization of Electrospun PVP Fibers}

Figure 6 shows the SEM images of the PVP fibers synthesized with and without dense $\mathrm{CO}_{2}$ at an applied voltage of $15 \mathrm{kV}$ using different concentrations $(6,8$, and $10 \mathrm{wt} \%)$ of the PVP-DCM solution. Without dense $\mathrm{CO}_{2}$, that is, under atmospheric conditions, and at a low polymer solution concentration $(6 \mathrm{wt} \%)$, the electrospun products showed irregular morphologies and blend (Figure 6a). Furthermore, at the same PVP concentration, almost no solidified electrospun product could be found on the electrospinning collector. The viscosity varies directly with the concentration of polymer, which, in turn, considerably influences the electrohydrodynamic process. Low viscosity can cause the surface tension of the PVP polymer solution to become high. Additionally, incomplete evaporation of the solvent during the electrospinning process occurred when a non-viscous polymer mixture was used as the starting solution, thereby causing the formation of non-solidified, wet electrospun products [38]. In contrast, spherical PVP particles and nascent strings were produced when an $8 \mathrm{wt} \%$ PVP polymer solution was utilized (Figure $6 \mathrm{c}$ ). The increase in the PVP concentration possibly reduced the surface tension and increased the viscosity of the PVP-DCM solution. At $10 \mathrm{wt} \%$ PVP, wet fibers were formed on the collector, as seen in Figure 6e.

Under dense $\mathrm{CO}_{2}$ environment (pressure: $5 \mathrm{MPa}$, temperature: $314 \mathrm{~K}$ ), the electrospun products formed using the $6 \mathrm{wt} \%$ PVP solution were mostly nano- and micro-sized spherical particles (Figure 6b). Additionally, almost no PVP polymer strings were synthesized under such operating conditions. Majority of the PVP particles had shriveled morphologies with uniform sizes. These findings imply the rapid evaporation of the solvent, DCM, which resulted in the shrinkage of the PVP particles. By increasing the PVP concentration from 6 to $8 \mathrm{wt} \%$ in the presence of dense $\mathrm{CO}_{2}$, smooth PVP polymer fibers with nonuniform sizes were fabricated (Figure 6d). These suggest that by changing the PVP concentration and, consequently, the surface tension of the PVP-DCM polymer solution, the morphologies of the electrospun products can be controlled from the accompanied tuning of the evaporation rate of the solvent. A further increase in the PVP concentration to $10 \mathrm{wt} \%$ led to the fabrication of smooth, bead-free fibers (Figure $6 \mathrm{f}$ ). The fibers were straight and appeared to have flat (ribbon-like) morphologies. In addition, the size was more uniform than that of the products fabricated from $8 \mathrm{wt} \%$ PVP-DCM solution. Similar results were obtained when the concentration of the PVP solution was changed during the electrospinning process in [39]. The results herein imply that when the concentration of the PVP feeding solution was increased, the entanglement of the PVP chains increased, which promoted the initiation and formation of smooth and uniform-sized electrospun fibers under ambient temperature and a dense $\mathrm{CO}_{2}$ environment. Thus, a $10 \mathrm{wt} \%$ PVP solution was chosen as the feed solution for the subsequent electrospinning experiments under dense $\mathrm{CO}_{2}$. 


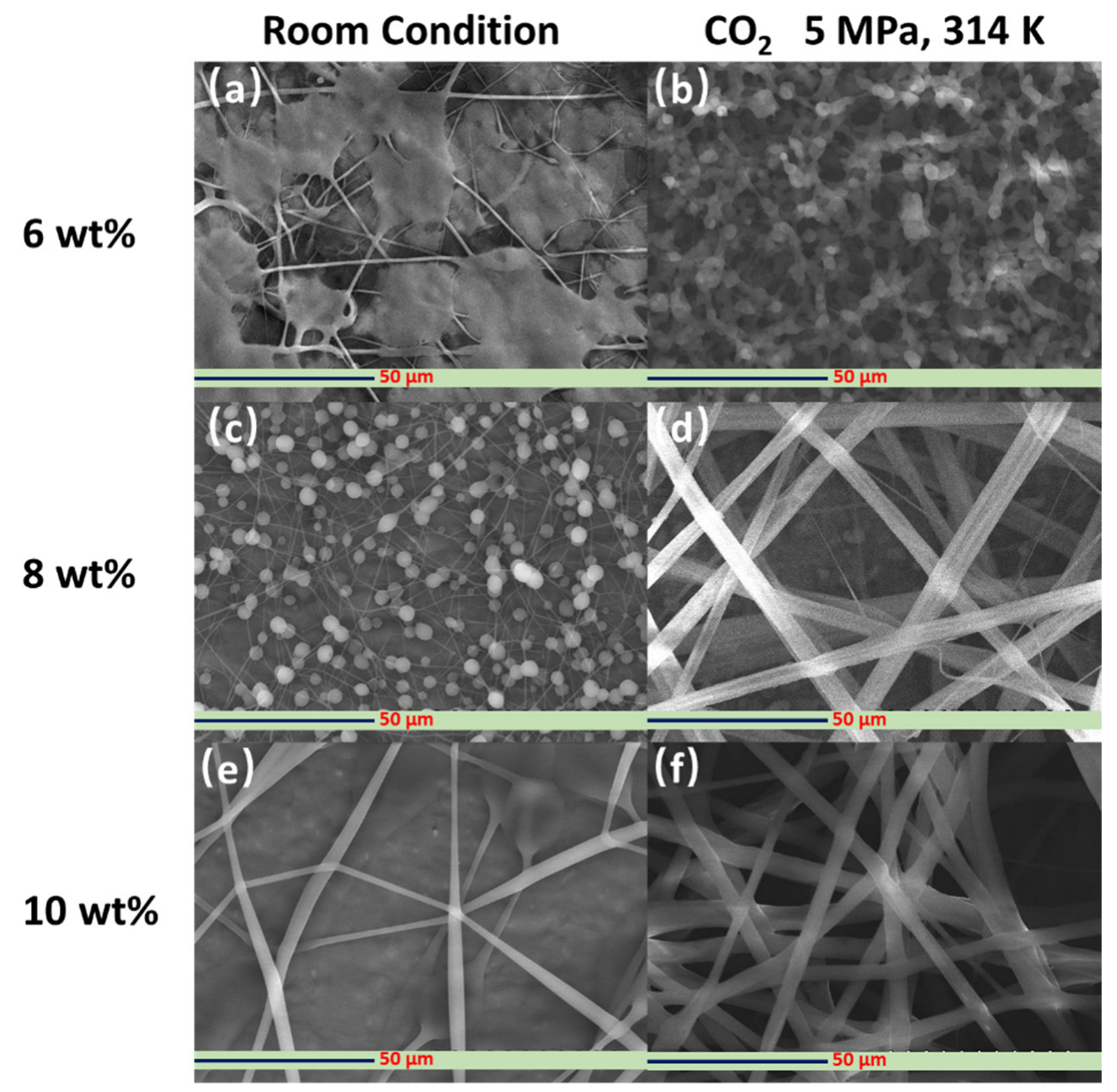

Figure 6. SEM images of the PVP fibers fabricated with $(\mathbf{b}, \mathbf{d}, \mathbf{f})$ and without $(\mathbf{a}, \mathbf{c}, \mathbf{e})$ dense $\mathrm{CO}_{2}$ at $15 \mathrm{kV}$ at different PVP concentrations $(6,8$, and $10 \mathrm{wt} \%)$.

Figure 7 shows the SEM images of the PVP fibers fabricated using a $10 \mathrm{wt} \%$ PVP polymer solution with and without dense $\mathrm{CO}_{2}$ at different applied voltages $(12,15$, and $18 \mathrm{kV})$. The applied voltage can determine the intensity of the generated electrical field during the electrospinning process, which significantly affects the characteristics of the PVP solution jet that produces the electrospun fibers. Therefore, the applied voltage is critical for determining the morphology of the electrospun fibers [40]. At higher applied voltages, the stretching stress on the solution jet typically increases, resulting in more delicate fibers. The generation of defects along the fibers is also promoted, increasing the likelihood of bead formation when using an inadequate concentration of the polymer feeding solution [41]. Under room conditions, wet fibers were successfully fabricated under all applied voltage conditions (Figure $7 \mathrm{a}, \mathrm{c}, \mathrm{e}$ ). However, under dense $\mathrm{CO}_{2}$ conditions, significant differences emerged. As shown in Figure $7 \mathrm{~b}$, the fibers fabricated at an applied voltage of $12 \mathrm{kV}$ were not straight. Defects in the fiber direction were also visible. These may be caused by the angle of PVP molecules in the long electrospinning process. At an applied voltage of $18 \mathrm{kV}$, the electrospun fibers appear to be slightly wet and not straight (Figure 7f), which is possibly caused by the low evaporation rate of DCM as a consequence of shorter electrospinning duration. Olive et al. [42] studied the effect of applied voltage on electrospun fibers and found similar results. Furthermore, the results show that a $15 \mathrm{kV}$ applied voltage was suitable to fabricate the electric field in the electrospinning process (Figure 7d). 


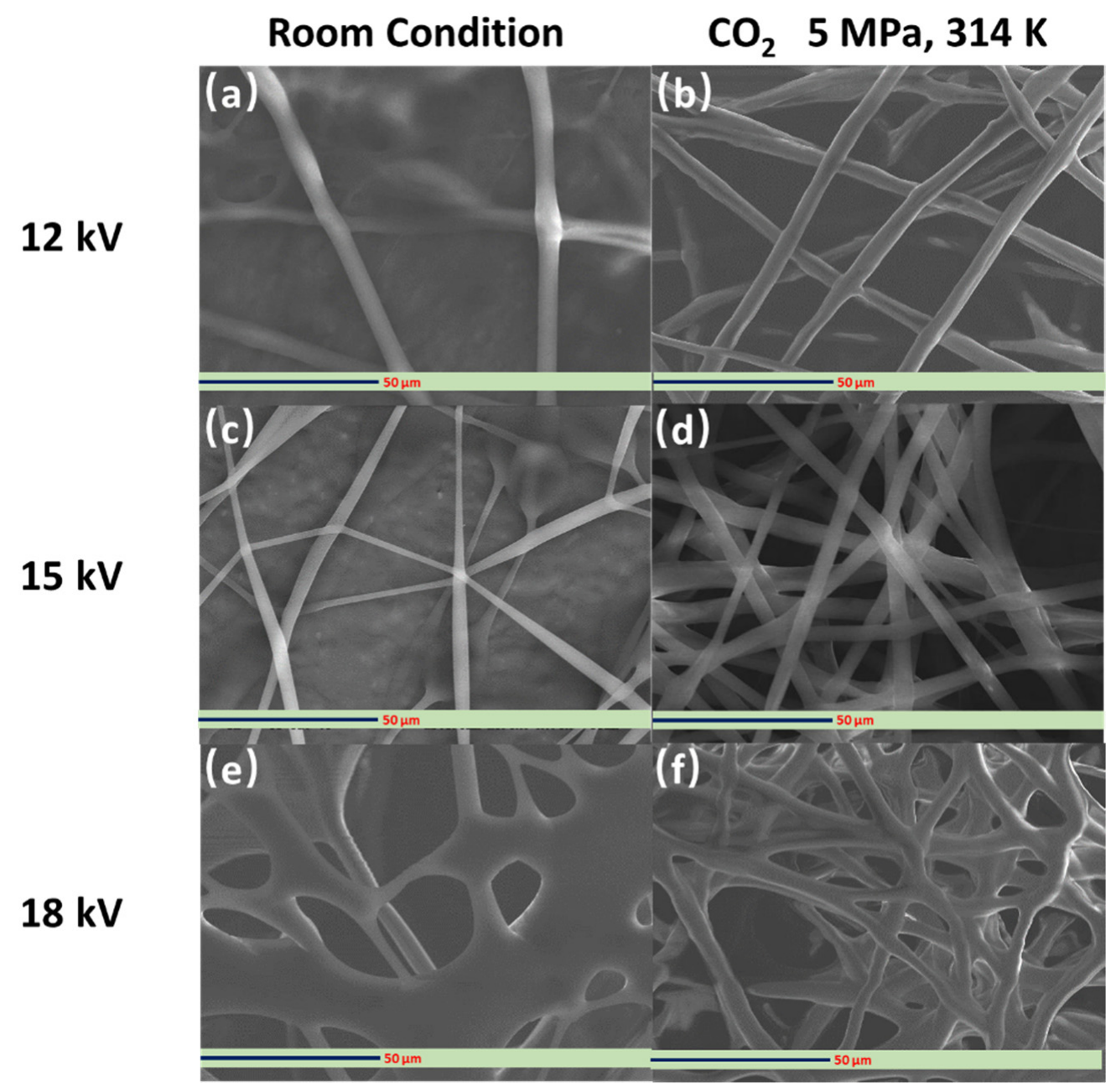

Figure 7. SEM images of PVP fibers fabricated from $10 \mathrm{wt} \%$ PVP solution with $(\mathbf{b}, \mathbf{d}, \mathbf{f})$ and without $(\mathbf{a}, \mathbf{c}, \mathbf{e})$ dense $\mathrm{CO}_{2}$ at various applied voltage $(12,15$, and $18 \mathrm{kV})$.

\subsection{Fabrication and Characterization of the Hollow PVP/Ag NP Composite Fibers}

Atmospheric parameters, such as temperature and relative humidity, may also impact the morphology of the electrospun fibers in addition to the characteristics of the polymer solution and the factors affecting the electrohydrodynamic process. Figure 8 shows the SEM images of the hollow PVP/Ag NP composite fibers fabricated using the $10 \mathrm{wt} \%$ PVP solution under various $\mathrm{CO}_{2}$ pressures (room conditions, 1, 3, and $5 \mathrm{MPa}$ ) at an applied voltage of $15 \mathrm{kV}$. Under room conditions, the electrospun products mainly consisted of wet fibers (Figure 8a). At a $1 \mathrm{MPa}-\mathrm{CO}_{2}$ pressure, the products are composed solely of nano-and microparticles. No PVP strings are formed (Figure 8b). After increasing the operating pressure to $3 \mathrm{MPa}$, spherical particles with PVP strings were formed (Figure 8c). At $5 \mathrm{MPa}$, the products exhibited a uniform, fine fiber morphology (Figure 8d). Bead formation was not observed, which was in agreement with the results of Huang et al. [43]. The average diameter of the electrospun fibers was approximately $5.02 \pm 1.87 \mu \mathrm{m}$. From the cross-sectional image in Figure 8e, the hollow structure of the fibers can be seen. The formation mechanism of such hollow fibers is as follows. First, the interaction between the polymer solution containing the Ag NPs and $\mathrm{CO}_{2}$ may accelerate the rapid evaporation of the solvent (DCM). The phase boundaries then emerge, and, eventually, the electrospun fiber PVP products. Even under supercritical conditions, $\mathrm{CO}_{2}$ is an extremely poor solvent for most polymers (including DCM) under the same conditions [44]. As such, superfluous $\mathrm{CO}_{2}$ can dissolve into the DCM-rich liquid phase of the PVP polymer solution with Ag NPs. Subsequently, the spinodal decomposition of the PVP-DCM solution might occur, 
resulting to the generation of a PVP-DCM solution network containing $\mathrm{CO}_{2}$-rich bubbles. Such bubbles in the polymer solution might coalesce and expand, forming a jet against the PVP-rich network and propelling PVP-rich phase bubbles radially outward against the inner surface of the jet. This explains the hollow-core-morphology of the electrospun PVP fibers containing Ag NPs. Wahyudiono et al. [45] also reported that hollow PVP fibers containing titanium dioxide $\left(\mathrm{TiO}_{2}\right)$ particles were formed using PVP-DCM containing $\mathrm{TiO}_{2} \mathrm{NP}$ solution by electrospinning under dense $\mathrm{CO}_{2}$. In that report, $\mathrm{TiO}_{2} \mathrm{NPs}$ were directly added to the PVP-DCM solution. However, because of the low solubility of $\mathrm{TiO}_{2}$ in the DCM solution, aggregation between the nanoparticles was observed, resulting in the non-dispersion of the particles on the surface of the fibers and the formation of micro-sized clusters in some areas.
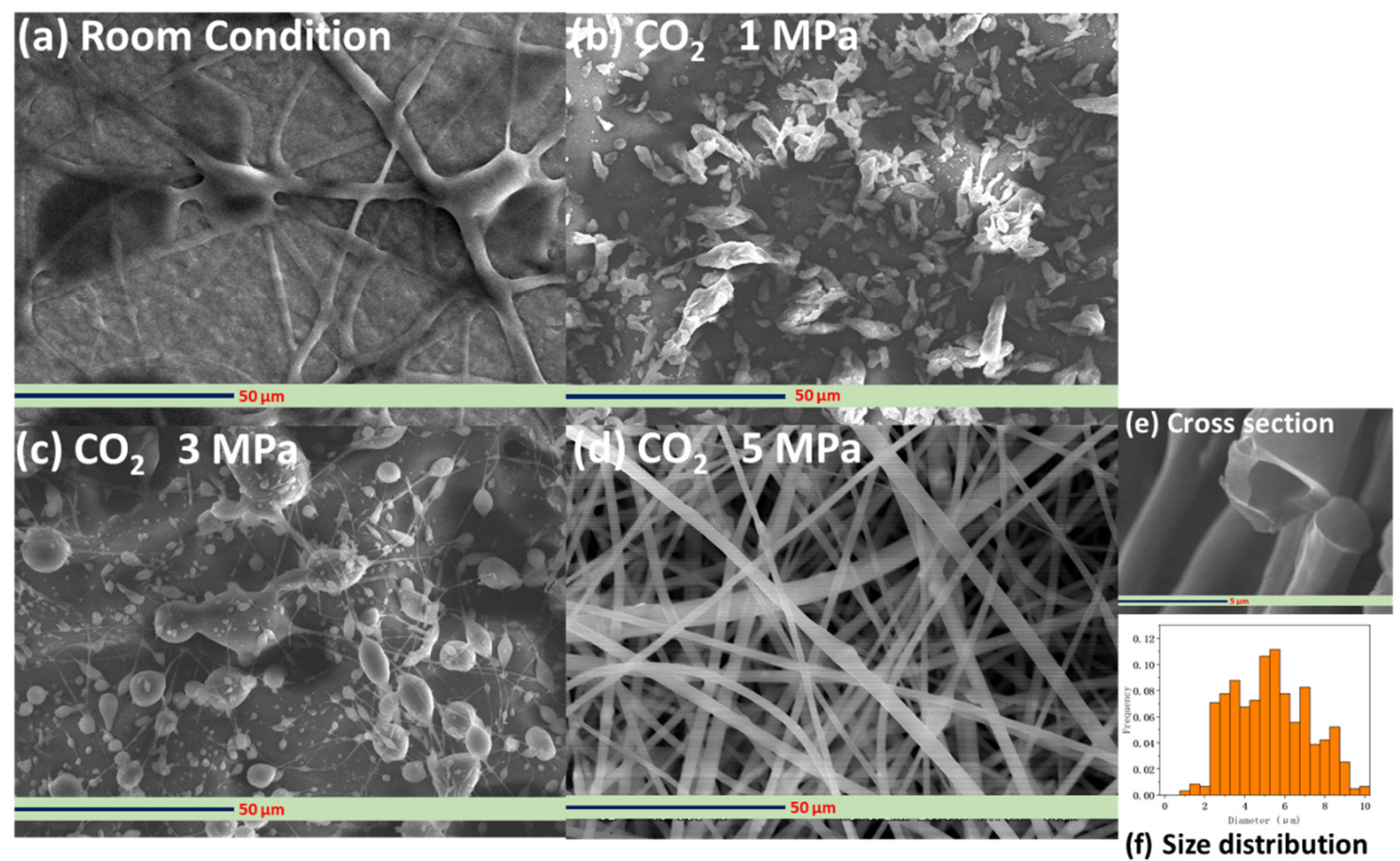

Average Size: $5.02 \pm 1.87 \mathrm{~nm}$

Figure 8. SEM images of the hollow PVP fibers fabricated from PVP solution containing Ag NPs under various $\mathrm{CO} 2$ conditions (room conditions, and 1,3, and $5 \mathrm{MPa}$ ), (a) Room condition; (b) $\mathrm{CO}_{2}$ $1 \mathrm{MPa}$; (c) $\mathrm{CO}_{2} 3 \mathrm{MPa}$; (d) $\mathrm{CO}_{2} 5 \mathrm{MPa}$; (e) cross section; (f) size distribution

Figure 9 shows the FT-IR spectra of the pure PVP fibers and of the PVP/Ag NP composite fibers electrospun at $5 \mathrm{MPa}$ and an applied voltage of $15 \mathrm{kV}$. The peak positions of the infrared bands and functional groups are summarized in Table 1 [24]. Herein, FT-IR spectra were used to analyze the possible structural changes in the PVP molecule, as well as the interaction between PVP and Ag NPs. The synthesized PVP/Ag NP composite fibers share the same FT-IR spectral properties with PVP, suggesting that the products fabricated by electrospinning had almost the same functional groups. Furthermore, this finding suggests that only a small amount of Ag NPs is present in the composite fibers. Hotaby et al. [46] also found a similar result by comparing the FT-IR spectra of pure PVP and PVP-Ag nanocomposite films. 


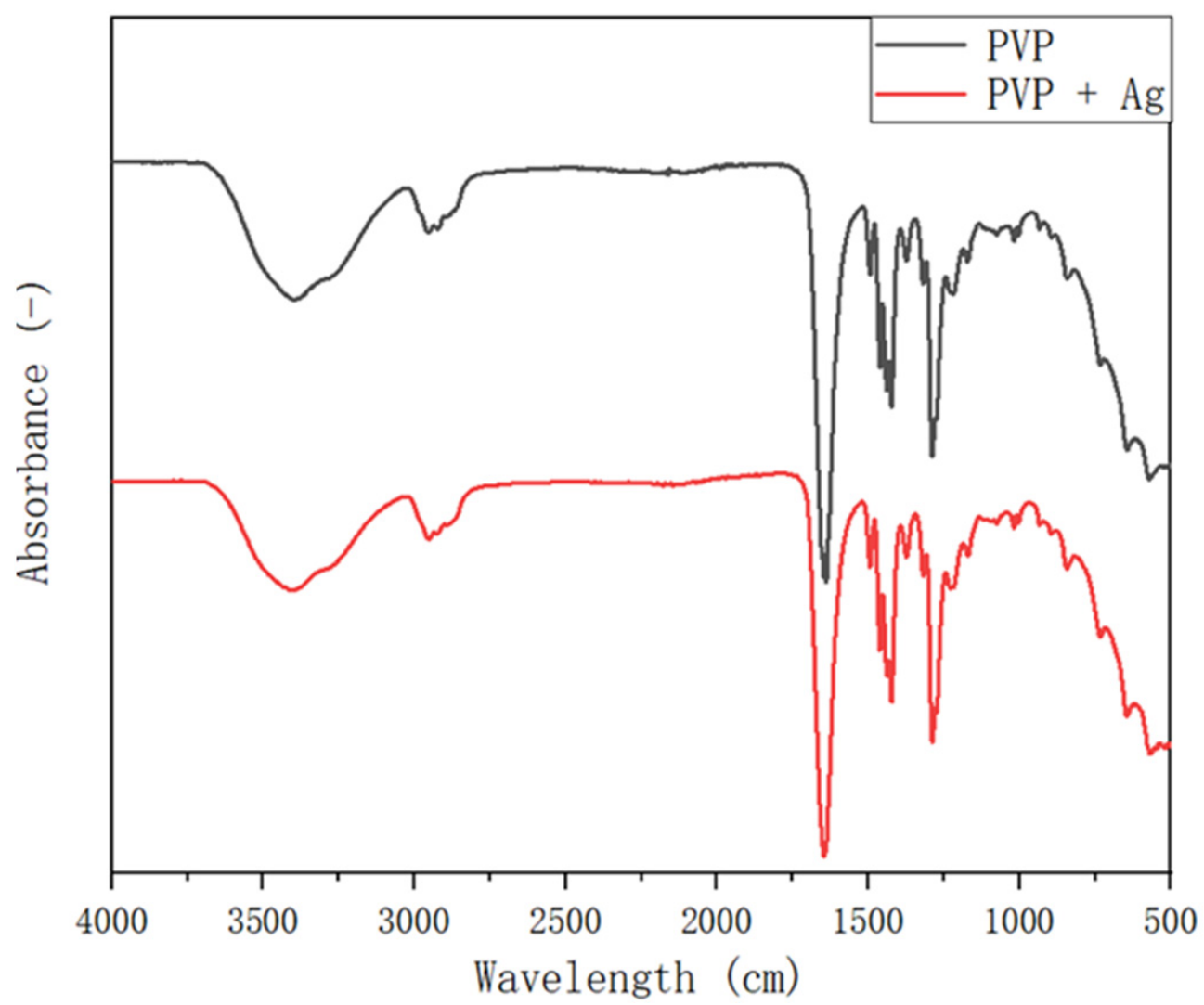

Figure 9. FT-IR spectrum of the pure PVP fibers and of the PVP/Ag NP composite fibers electrospun at $5 \mathrm{MPa}$ and applied voltage of $15 \mathrm{kV}$.

Table 1. Typical bands in infrared spectra of PVP.

\begin{tabular}{ll}
\hline Wavenumber $\left(\mathbf{c m}^{-\mathbf{1}}\right)$ & Functional Groups \\
\hline $3435.47-3415.45$ and $1286.37-1284.84$ & N-H stretching vibration and C-N stretching vibration from pyrrolidone structure \\
\hline $2950.02-2921.18$ & C-H stretching for aliphatic compounds \\
\hline $1651.12-1650.46$ & Carbonyl (C-O) stretching of the five-membered cyclic lactam structure \\
\hline $1493.25-1493.16$ and 1461.00-1460.82 & C =C aromatic stretching \\
\hline $1422.11-1421.63$ and 1372.91-1372.32 & C-H bending vibration from methylene groups (aliphatic compound) \\
\hline $843.82-843.29$ & =C-H bending vibrations (unsaturated compounds)
\end{tabular}

Figure 10 shows the XRD patterns of the pure PVP fibers and of the PVP/Ag NP composite fibers electrospun at $5 \mathrm{MPa}$ at an applied voltage of $15 \mathrm{kV}$. Two diffused halo peaks close to $2 \theta=11.78^{\circ}$ and $21.94^{\circ}$ were observed in the XRD pattern of the pure PVP fiber. This is in good agreement with the results reported by Li et al. [47]. In contrast, the XRD pattern of the PVP/Ag NP composite fibers showed peaks at $2 \theta=11.47^{\circ}$ and $21.63^{\circ}$. These results also point out the meager amount of Ag NPs in the synthesized PVP/Ag NP composite. These findings may also be due to the masking of the peaks corresponding to Ag NPs by the PVP fibers [46]. 


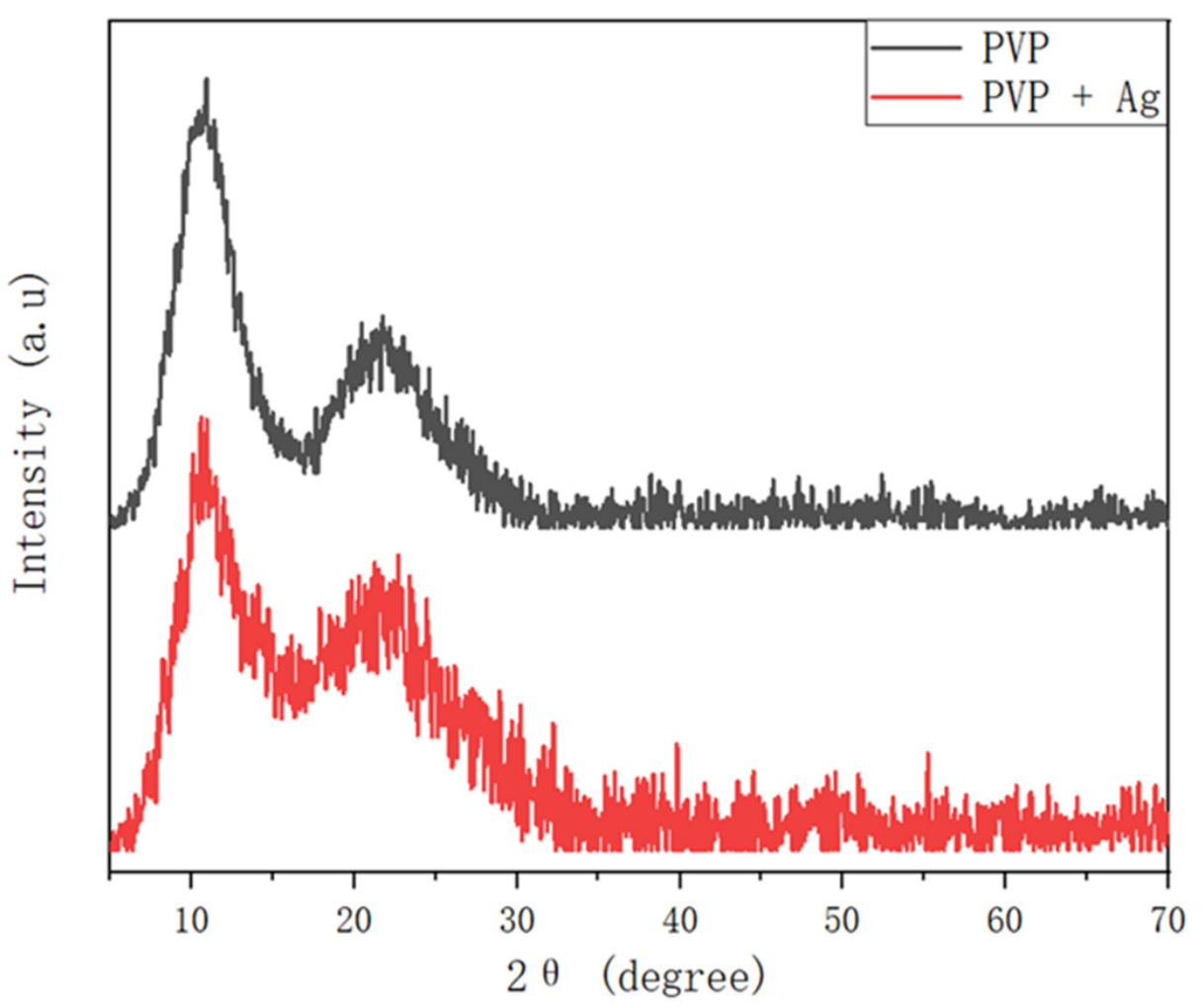

Figure 10. XRD pattern of the pure PVP fibers and of the PVP/Ag NP composite fibers electrospun at $5 \mathrm{MPa}$ at an applied voltage of $15 \mathrm{kV}$.

Figure 11 shows the TGA curves of the pure PVP fibers and of the PVP/Ag NP composite fibers (synthesized at $5 \mathrm{MPa}$ and an applied voltage of $15 \mathrm{kV}$ ). By measuring the weight variations in response to rising temperature at a constant heating rate, TGA may evaluate a material's thermal stability and the proportion of the volatile component. Heat transfer and medium diffusion may be used to explain this phenomenon [48]. In this experiment, TGA was carried out at an airflow of $100 \mathrm{~mL} \mathrm{~min}^{-1}$ and a heating rate of $10^{\circ} \mathrm{C} \mathrm{min}^{-1}$. Pure PVP and electrospun PVP fibers containing Ag NPs were weighed (about $0.6-1 \mathrm{mg}$ ) in aluminum pans. After that, the weight loss of these two groups was monitored during the heating process from 40 to $800{ }^{\circ} \mathrm{C}$. The thermal degradation of the pure PVP fibers and of the PVP/Ag NP composite fibers was considered to be the reason for the weight loss observed in Figure 11. During the TG analysis, several sections of loss were observed. The initial weight loss observed at $80^{\circ} \mathrm{C}$ is possibly due to the evolution of the volatile compounds from pure PVP and electrospun PVP/Ag NP composite fibers. Thereafter, the thermal deterioration of the electrospun products began at approximately $270{ }^{\circ} \mathrm{C}$. This was followed by a considerable weight loss until $630{ }^{\circ} \mathrm{C}$ from the primary devolatilization of the fibers. No further change in weight was observed for both samples beyond this temperature. In general, the polymer matrix-nanoparticle structure can enhance the thermal stability [49]. During the rapid evaporation of DCM, Ag NPs may be dispersed into the PVP matrix. Then, a powerful interaction between PVP and Ag NPs forms through hydrogen bonding in the PVP matrix. Nevertheless, as can be seen in Figure 11, there were no significant differences in the thermal degradation curves of the pure PVP and of the PVP/Ag NP composite fibers possibly due to the low amount of Ag NPs added to the PVP-DCM solution. Consequently, the thermal stability of the PVP/Ag NP composite fibers may not be considerably modified. 


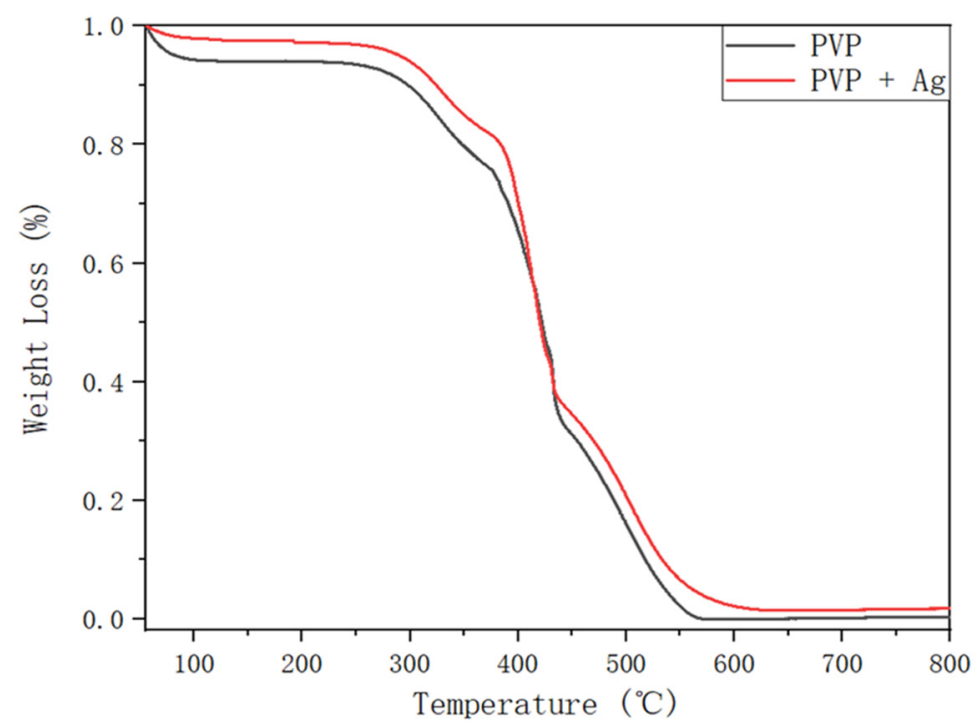

Figure 11. TGA curves of the pure PVP fibers and of the PVP/Ag NP composite fibers electrospun at $5 \mathrm{MPa}$ and applied voltage of $15 \mathrm{kV}$.

The residue weight $(0.025 \mathrm{mg})$ observed the TG curve of PVP/Ag NP composite fibers $\left(0.73 \mathrm{mg}\right.$ ) at temperatures beyond $630^{\circ} \mathrm{C}$ reveal the existence of $\mathrm{Ag}$ NPs in the electrospun PVP fibers (Figure 11). This permits the separation of the nanoparticles from the polymer, allowing for XPS examination of the sample to acquire precise information on the chemical state of the metal. XPS examination was used after TGA to verify the presence of Ag NPs in the residue. Figure 12 shows the XPS spectra of the residue obtained after the TG analysis of the PVP/Ag NP fibers (5 MPa dense $\mathrm{CO}_{2}$ and an applied voltage of $15 \mathrm{kV}$ ). Peaks were detected at 368 and $374 \mathrm{eV}$ in the spectra, indicating the presence of Ag NPs in the residue after the TG analysis [50].

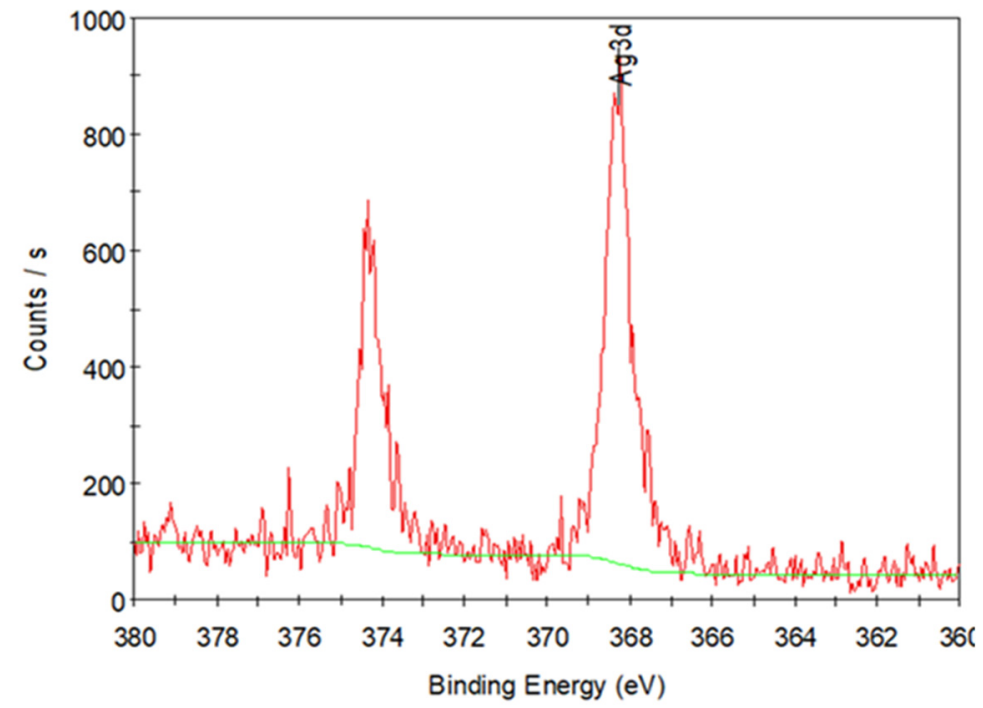

Figure 12. XPS spectra of the residue obtained after the TG analysis of the PVP/Ag NP fibers (5 MPa and applied voltage of $15 \mathrm{kV}$ ).

\section{Conclusions}

In this study, Ag NPs were initially synthesized through ultrasonic irradiation using starch as a stabilizing and reducing agent of the $\mathrm{AgNO}_{3}$ solution. The sonochemical reduction route has an extraordinary potential for generating Ag NPs with a desirable particle size. The ultrasonic frequency and time were found to have a considerable impact 
on the morphology of the fabricated Ag NPs. In addition, electrospinning of PVP fibers with different PVP concentrations $(6,8$, and $10 \mathrm{wt} \%)$ at $12-18 \mathrm{kV}$ was investigated under room conditions and dense $\mathrm{CO}_{2}$ environment (temperature: $313 \mathrm{~K}$, pressure: $5 \mathrm{MPa}$ ). The electrospinning products were compared using SEM images, and suitable parameters for the synthesis of hollow PVP fibers were determined. Thereafter, the electrospinning of PVP-Ag NP fibers was studied at different CO pressures. SEM images revealed that the electrospun PVP/Ag NP composite fibers exhibited the same morphology and hollow structure as the pure PVP fibers. FT-IR spectroscopy and XRD analysis revealed that the pure PVP fibers and PVP/Ag NP composite fibers exhibited similar properties. In addition, XPS confirmed the presence of Ag NPs in the residue obtained after the TG analysis of the hollow PVP/Ag NP composite. Thus, the results showed that polymer fibers with hollow structures containing metal NPs can be fabricated by electrospinning under dense $\mathrm{CO}_{2}$.

Author Contributions: X.H. and W.: conceptualization, investigation, methodology, data curation, visualization, and writing of the original draft. J.H. and L.Z.: Investigation and data curation. S.M.: Supervision, H.K.: Writing-review and editing, project administration, resources, and supervision. M.G.: Project administration, resources, and supervision. All authors have read and agreed to the published version of the manuscript.

Funding: This work was supported by JSPS KAKENHI (Grant Number JP20H02515) and JST SICORP (Grant Number JPMJSC18H1), Japan.

Institutional Review Board Statement: Not applicable.

Informed Consent Statement: Not applicable.

Data Availability Statement: The data presented in this study are available on request from the corresponding author.

Conflicts of Interest: The authors declare no conflict of interest.

\section{References}

1. Shrivas, K.; Nirmalkar, N.; Deb, M.K.; Dewangan, K.; Nirmalkar, J.; Kumar, S. Application of functionalized silver nano-particles as a biochemical sensor for selective detection of lysozyme protein in milk sample. Spectrochim. Acta Part A Mol. Biomol. Spectrosc. 2019, 213, 127-133. [CrossRef]

2. Franci, G.; Falanga, A.; Galdiero, S.; Palomba, L.; Rai, M.; Morelli, G.; Galdiero, M. Silver nanoparticles as potential antibacterial agents. Molecules 2015, 20, 8856-8874. [CrossRef]

3. Chimentao, R.; Kirm, I.; Medina, F.; Rodriguez, X.; Cesteros, Y.; Salagre, P.; Sueiras, J. Different morphologies of silver nanoparticles as catalysts for the selective oxidation of styrene in the gas phase. Chem. Commun. 2004, 7, 846-847. [CrossRef]

4. Zaarour, M.; El Roz, M.; Dong, B.; Retoux, R.; Aad, R.; Cardin, J.; Dufour, C.; Gourbilleau, F.; Gilson, J.-P.; Mintova, S. Photochemical preparation of silver nanoparticles supported on zeolite crystals. Langmuir 2014, 30, 6250-6256. [CrossRef] [PubMed]

5. Hu, X.; Takada, N.; Machmudah, S.; Wahyudiono; Kanda, H.; Goto, M. Ultrasonic-enhanced fabrication of metal nanoparticles by laser ablation in liquid. Ind. Eng. Chem. Res. 2020, 59, 7512-7519. [CrossRef]

6. Wang, H.; Qiao, X.; Chen, J.; Ding, S. Preparation of silver nanoparticles by chemical reduction method. Colloids Surf. A Physicochem. Eng. Asp. 2005, 256, 111-115. [CrossRef]

7. Khaydarov, R.A.; Khaydarov, R.R.; Gapurova, O.; Estrin, Y.; Scheper, T. Electrochemical method for the synthesis of silver nanoparticles. J. Nanoparticle Res. 2009, 11, 1193-1200. [CrossRef]

8. Chen, W.; Cai, W.; Zhang, L.; Wang, G.; Zhang, L. Sonochemical processes and formation of gold nanoparticles within pores of mesoporous silica. J. Colloid Interface Sci. 2001, 238, 291-295. [CrossRef] [PubMed]

9. Darroudi, M.; Zak, A.K.; Muhamad, M.; Huang, N.; Hakimi, M. Green synthesis of colloidal silver nanoparticles by sonochemical method. Mater. Lett. 2012, 66, 117-120. [CrossRef]

10. Mizukoshi, Y.; Takagi, E.; Okuno, H.; Oshima, R.; Maeda, Y.; Nagata, Y. Preparation of platinum nanoparticles by sonochemical reduction of the $\mathrm{Pt}(\mathrm{IV})$ ions: Role of surfactants. Ultrason. Sonochem. 2001, 8, 1-6. [CrossRef]

11. Shin, H.S.; Yang, H.J.; Kim, S.B.; Lee, M.S. Mechanism of growth of colloidal silver nanoparticles stabilized by polyvinyl pyrrolidone in $\gamma$-irradiated silver nitrate solution. J. Colloid Interface Sci. 2004, 274, 89-94. [CrossRef] [PubMed]

12. Kumar, B.; Smita, K.; Cumbal, L.; Debut, A.; Pathak, R.N. Sonochemical synthesis of silver nanoparticles using starch: A comparison. Bioinorg. Chem. Appl. 2014, 2014, 784268. [CrossRef] [PubMed]

13. Božanić, D.K.; Djoković, V.; Blanuša, J.; Nair, P.; Georges, M.; Radhakrishnan, T. Preparation and properties of nano-sized Ag and Ag 2 S particles in biopolymer matrix. Eur. Phys. J. E 2007, 22, 51-59. [CrossRef] 
14. Rahmati, M.; Mills, D.K.; Urbanska, A.M.; Saeb, M.R.; Venugopal, J.R.; Ramakrishna, S.; Mozafari, M. Electrospinning for tissue engineering applications. Prog. Mater. Sci. 2021, 117, 100721. [CrossRef]

15. Kim, G.-M.; Wutzler, A.; Radusch, H.-J.; Michler, G.H.; Simon, P.; Sperling, R.A.; Parak, W.J. One-dimensional arrangement of gold nanoparticles by electrospinning. Chem. Mater. 2005, 17, 4949-4957. [CrossRef]

16. Chinnappan, A.; Baskar, C.; Baskar, S.; Ratheesh, G.; Ramakrishna, S. An overview of electrospun nanofibers and their application in energy storage, sensors and wearable/flexible electronics. J. Mater. Chem. C 2017, 5, 12657-12673. [CrossRef]

17. Cheung, T.W.; Li, L. A review of hollow fibers in application-based learning: From textiles to medical. Text. Res. J. 2019, 89, 237-253. [CrossRef]

18. Lasseuguette, E.; Rouch, J.-C.; Remigy, J.-C. Hollow-fiber coating: Application to preparation of composite hollow-fiber membrane for gas separation. Ind. Eng. Chem. Res. 2013, 52, 13146-13158. [CrossRef]

19. Ji, X.; Su, Z.; Wang, P.; Ma, G.; Zhang, S. Tethering of nicotinamide adenine dinucleotide inside hollow nanofibers for high-yield synthesis of methanol from carbon dioxide catalyzed by coencapsulated multienzymes. ACS Nano 2015, 9, 4600-4610. [CrossRef]

20. Wahyudiono; Machmudah, S.; Murakami, K.; Okubayashi, S.; Goto, M. Generation of PVP fibers by electrospinning in one-step process under high-pressure $\mathrm{CO}_{2}$. Int. J. Ind. Chem. 2013, 4, 27. [CrossRef]

21. Kirby, C.F. Phase behavior of polymers in supercritical fluid solvents. Chem. Rev. 1999, 99, 565-602. [CrossRef] [PubMed]

22. Wahyudiono; Machmudah, S.; Kanda, H.; Okubayashi, S.; Goto, M. Formation of PVP hollow fibers by electrospinning in one-step process at sub and supercritical $\mathrm{CO}_{2}$. Chem. Eng. Process. Process Intensif. 2014, 77, 1-6. [CrossRef]

23. Wahyudiono; Okamoto, K.; Machmudah, S.; Kanda, H.; Goto, M. Generation of multihollow structured poly (methyl methacrylate) fibers by electrospinning under pressurized $\mathrm{CO}_{2}$. Polym. Eng. Sci. 2016, 56, 752-759. [CrossRef]

24. Ozawa, H.; Machmudah, S.; Wahyudiono; Kanda, H.; Goto, M. Electrospinning of poly (vinyl pyrrolidone) fibers containing metal oxide nanoparticles under dense $\mathrm{CO}_{2}$. Res. Chem. Intermed. 2018, 44, 2215-2230. [CrossRef]

25. Suttiponparnit, K.; Jiang, J.; Sahu, M.; Suvachittanont, S.; Charinpanitkul, T.; Biswas, P. Role of surface area, primary particle size, and crystal phase on titanium dioxide nanoparticle dispersion properties. Nanoscale Res. Lett. 2011, 6, 1-8. [CrossRef]

26. Vatansever, H.Ç.; Meriçboyu, A.E. Production of antibacterial polyvinylpyrrolidone nanofibers containing silver nanoparticles via electrospinning method. MANAS J. Eng. 2019, 7, 13-23.

27. Yu, D.-G.; Teng, M.-Y.; Chou, W.-L.; Yang, M.-C. Characterization and inhibitory effect of antibacterial PAN-based hollow fiber loaded with silver nitrate. J. Membr. Sci. 2003, 225, 115-123. [CrossRef]

28. Frank, A.J.; Cathcart, N.; Maly, K.E.; Kitaev, V. Synthesis of silver nanoprisms with variable size and investigation of their optical properties: A first-year undergraduate experiment exploring plasmonic nanoparticles. J. Chem. Educ. 2010, 87, 1098-1101. [CrossRef]

29. Sharma, G.; Nam, J.-S.; Sharma, A.R.; Lee, S.-S. Antimicrobial potential of silver nanoparticles synthesized using medicinal herb coptidis rhizome. Molecules 2018, 23, 2268. [CrossRef]

30. Takada, N.; Fujikawa, A.; Koshizaki, N.; Sasaki, K. Effect of ultrasonic wave on the syntheses of Au and ZnO nanoparticles by laser ablation in water. Appl. Phys. A 2013, 110, 835-839. [CrossRef]

31. Okitsu, K.; Ashokkumar, M.; Grieser, F. Sonochemical synthesis of gold nanoparticles: Effects of ultrasound frequency. J. Phys. Chem. B 2005, 109, 20673-20675. [CrossRef] [PubMed]

32. Salkar, R.; Jeevanandam, P.; Aruna, S.; Koltypin, Y.; Gedanken, A. The sonochemical preparation of amorphous silver nanoparticles. J. Mater. Chem. 1999, 9, 1333-1335. [CrossRef]

33. Zhang, G.; Jasinski, J.B.; Howell, J.L.; Patel, D.; Stephens, D.P.; Gobin, A.M. Tunability and stability of gold nanoparticles obtained from chloroauric acid and sodium thiosulfate reaction. Nanoscale Res. Lett. 2012, 7, 337. [CrossRef] [PubMed]

34. Raffi, M.; Hussain, F.; Bhatti, T.; Akhter, J.; Hameed, A.; Hasan, M. Antibacterial characterization of silver nanoparticles against E. coli ATCC-15224. J. Mater. Sci. Technol. 2008, 24, 192-196.

35. Doktycz, S.J.; Suslick, K.S. Interparticle collisions driven by ultrasound. Science 1990, 247, 1067-1069. [CrossRef] [PubMed]

36. Prozorov, T.; Prozorov, R.; Suslick, K.S. High velocity interparticle collisions driven by ultrasound. J. Am. Chem. Soc. 2004, 126, 13890-13891. [CrossRef]

37. Mahdavi, R.; Talesh, S.S.A. The effect of ultrasonic irradiation on the structure, morphology and photocatalytic performance of $\mathrm{ZnO}$ nanoparticles by sol-gel method. Ultrason. Sonochem. 2017, 39, 504-510. [CrossRef] [PubMed]

38. Levitt, A.S.; Vallett, R.; Dion, G.; Schauer, C.L. Effect of electrospinning processing variables on polyacrylonitrile nanoyarns. J. Appl. Polym. Sci. 2018, 135, 46404. [CrossRef]

39. Wahyudiono; Ozawa, H.; Machmudah, S.; Kanda, H.; Goto, M. Electrospraying technique under pressurized carbon dioxide for hollow particle production. React. Funct. Polym. 2019, 142, 44-52. [CrossRef]

40. Beachley, V.; Wen, X. Effect of electrospinning parameters on the nanofiber diameter and length. Mater. Sci. Eng. C 2009, 29, 663-668. [CrossRef]

41. Liu, Y.; Dong, L.; Fan, J.; Wang, R.; Yu, J.Y. Effect of applied voltage on diameter and morphology of ultrafine fibers in bubble electrospinning. J. Appl. Polym. Sci. 2011, 120, 592-598. [CrossRef]

42. Can-Herrera, L.; Oliva, A.; Dzul-Cervantes, M.; Pacheco-Salazar, O.; Cervantes-Uc, J. Morphological and mechanical properties of electrospun polycaprolactone scaffolds: Effect of applied voltage. Polymers 2021, 13, 662. [CrossRef]

43. Huang, S.; Zhou, L.; Li, M.-C.; Wu, Q.; Kojima, Y.; Zhou, D. Preparation and properties of electrospun poly (vinyl pyrrolidone)/cellulose nanocrystal/silver nanoparticle composite fibers. Materials 2016, 9, 523. [CrossRef] 
44. Shin, M.S.; Lee, J.H.; Kim, H. Phase behavior of the poly (vinyl pyrrolidone)+ dichloromethane+ supercritical carbon dioxide system. Fluid Phase Equilib. 2008, 272, 42-46. [CrossRef]

45. Wahyudiono; Okamoto, K.; Machmudah, S.; Kanda, H.; Goto, M. Hydrophilic polymer composites synthesized by electrospinning under dense carbon dioxide. AIP Conf. Proc. 2015, 1699, 040010.

46. El Hotaby, W.; Sherif, H.; Hemdan, B.; Khalil, W.; Khalil, S. Assessment of in situ-prepared polyvinylpyrrolidone-silver nanocomposite for antimicrobial applications. Acta Phys. Pol. Part A 2017, 131, 1554-1560. [CrossRef]

47. Li, X.-G.; Kresse, I.; Springer, J.; Nissen, J.; Yang, Y.-L. Morphology and gas permselectivity of blend membranes of polyvinylpyridine with ethylcellulose. Polymer 2001, 42, 6859-6869. [CrossRef]

48. Arenillas, A.; Rubiera, F.; Pevida, C.; Pis, J. A comparison of different methods for predicting coal devolatilisation kinetics. J. Anal. Appl. Pyrolysis 2001, 58, 685-701. [CrossRef]

49. Chrissafis, K.; Bikiaris, D. Can nanoparticles really enhance thermal stability of polymers? Part I: An overview on thermal decomposition of addition polymers. Thermochimica Acta 2011, 523, 1-24. [CrossRef]

50. Zhang, Z.; Zhang, X.; Xin, Z.; Deng, M.; Wen, Y.; Song, Y. Synthesis of monodisperse silver nanoparticles for ink-jet printed flexible electronics. Nanotechnology 2011, 22, 425601. [CrossRef] 